JURNAI, RIS'II
IAll $\begin{gathered}\text { (Rekayasa Sistem dan Teknologi Informasi) } \\ \text { Vol.4No.6 (2020)1102-1109 }\end{gathered}$

\title{
Alat Deteksi Jatuh Berbiaya Murah dengan Tracking Position untuk Pasien Vertigo dan Sinkop

\author{
Yulastri $^{1}$, Era Madona ${ }^{2}$, Muhammad irmansyah $^{3}$, Anggara Nasution ${ }^{4}$ \\ 1,2,3,4 Jurusan Teknik Elektro Politeknik Negeri Padang \\ 2 emadona38@gmail.com
}

\begin{abstract}
In this study we propose a low-cost portable device to monitor the vertigo and syncope patients whether normal, dizziness or falls. The purpose of this study is design and manufactures a device using an accelerometer sensor to determining the condition of patients who are at risk of vertigo and syncope. The patient's condition is detected by accelerometer which read the values of the $x, y$ and $z$ axes to determine condition normal, dizzy, or fall. This device also uses a real time clock to remind the patient to take medication three times a day. The device outputs are LCD Oled, Voice, and SMS notification. If the patient condition is falls an SMS notification will be sent, the dizzy condition vertigo patient will press the panic button first and then an SMS notification will be sent. The results of tests carried out on the equipment can send SMS and phone calls at an angle of $\left(50^{\circ}-\right.$ $\left.70^{\circ}\right)=Y\left(40^{\circ}-20^{\circ}\right)=X$, in a fainting state and falling. The test results of the navigation module prove that the GPS module can determine the exact location by moving the GPS module reading position to a small test point with an average of 2.97 meters. Overall the tool can function properly.
\end{abstract}

Keywords: vertigo, accelerometer, notification, GPS, SMS, syncope

\begin{abstract}
Abstrak
Pada penelitian ini kami mengusulkan alat portable berbiaya rendah untuk mengawasi dan memantau pasien beresiko vertigo apakah terjadi insiden pusing, jatuh atau tidak. Tujuan dari penelitian ini adalah merancang dan membuat alat menggunakan sensor accelerometer yang berguna untuk mengetahui kondisi pasien yang beresiko vertigo dan sinkop. Untuk mengetahui kondisi pasien digunakan sensor accelerometer yang akan membaca nilai sumbu $\mathrm{x}, \mathrm{y}$, dan $\mathrm{z}$ untuk menentukan kondisi baikbaik saja, pusing, atau jatuh. Selain itu juga menggunakan real time clock untuk pengingat minum obat tiga kali sehari. Output yang digunakan adalah LCD Oled, Suara, dan SMS. Saat kondisi jatuh akan dikirim notifikasi SMS. Sedangkan untuk kondisi pusing penderita vertigo menekan push button panik terlebih dahulu kemudian akan dikirim notifikasi SMS. Hasil pengujian yang dilakukan pada alat alat dapat melakukan pengiriman SMS dan panggilan telepon pada sudut $\left(50^{\circ}-70^{\circ}\right)=\mathrm{Y}\left(40^{\circ}-20^{\circ}\right)$ $=\mathrm{X}$, di kondisi pingsan dan jatuh. Hasil pengujian modul navigasi membuktikan modul GPS dapat menentukan lokasi dengan tepat dengan pergesaran posisi pembacaan modul GPS ke titik pengujian kecil dengan rata-rata 2,97 meter. Secara keseluruhan alat dapat berfungsi dengan baik.
\end{abstract}

Kata kunci: vertigo, accelerometer, notification, GPS,SMS, syncope

\section{Pendahuluan}

Sistem keseimbangan merupakan sebuah sistem yang penting untuk kehidupan manusia. Sistem keseimbangan membuat manusia mampu menyadari kedudukan terhadap ruangan sekitar. Keseimbangan merupakan sebuah sistem yang saling berintegrasi yaitu sistem visual, vestibular, sistem propioseptik, dan serebelar. Gangguan pada sistem keseimbangan tersebut akan menimbulkan berbagai keluhan, diantaranya berupa sensasi berputar yang sering disebut vertigo. Vertigo merupakan keluhan yang sering dijumpai digambarkan sebagai sensasi berputar, rasa oleng, tidak stabil (giddiness, unsteadiness) dan rasa pusing (dizziness) [1-
3]. Vertigo merupakan masalah kesehatan yang nyata pada masyarakat. Pasien mengalami kesulitan dalam mengungkapkan timbulnya gejala. Menurut survey dari Department of Epidemiology, Robert Koch Institute Germany pada populasi umum di Berlin tahun 2007, prevalensi vertigo dalam 1 tahun $0,9 \%$, vertigo akibat migren $0,89 \%$, untuk BPPV $1,6 \%$, vertigo akibat Meniere's Disease $0.51 \%$. Di Indonesia, data kasus di R.S. Dr Kariadi Semarang menyebutkan bahwa kasus vertigo menempati urutan ke 5 kasus terbanyak yang dirawat di bangsal saraf. Pengaruh dari vertigo pada seseorang adalah hilangnya fungsi syaraf secara tiba-tiba dan mengalami pusing sehingga seseorang tersebut dapat terjatuh dan pingsan. Tidak hanya vertigo,

Diterima Redaksi : 09-11-2020 | Selesai Revisi : 17-11-2020 | Diterbitkan Online : 20-12-2020 
penyebab pingsan atau dalam dunia medis disebut pemantauan pada pasien vertigo dan sinkop saat sinkop bisa disebabkan oleh, tekanan darah rendah atau beraktivitas.

pembuluh darah yang melebar, detak jantung tidak teratur, hipoglikemia dan penyakit saraf [4]. Dikarenakan gejala vertigo dan sinkop munculnya Metode yang digunakan dalam penelitian ini adalah mendadak maka diperlukan suatu tindakan berupa pembuatan prototype alat yang dimulai dari studi pengawasan untuk seseorang yang pernah mengalami literature, perancangan system, perancangan perangkat hal tersebut, karena jika tidak cepat dilakukan tindakan keras (hardware), perancangan perangkat lunak bisa menyebabkan gejala lebih parah seperti stroke (software), pengujian hardware, software dan analisa bahkan meninggal dunia[5-6].

Pengawasan ini sangat penting dilakukan agar tidak terjadi hal-hal yang tidak diinginkan. Keluarga terdekat harus selalu menemani dan mengawasi apa saja yang mereka kerjakan. Sehingga apabila terjadi sesuatu dapat langsung ditangani agar tidak berakibat fatal. Akan tetapi hal tersebut bukanlah hal yang mudah dilakukan karena para keluarga juga memiliki kesibukan masingmasing. Kecemasan muncul ketika para keluarga tidak dapat memantau apa yang terjadi dengan pasien vertigo. Untuk mengawasi dan memantau pasien vertigo apakah terjadi insiden pusing, jatuh atau tidak, diperlukan suatu alat yang berfungsi untuk mengetahui keadaan posisi pasien itu sendiri dari jarak dekat maupun jauh. Beberapa penelitian terkait monitoring kesehatan telah dilakukan diantaranya untuk monitoring detak jantung [7-9] dan suhu tubuh [10-11] berbasis IoT. Penelitian yang dilakukan juga dapat melakukan diagnosis menggunakan smartphone [12,13,14] dan berbasis website [15-16]. Sensor yang digunakan pada penelitian ini menggunakan pulse sensor dan DS18b20 sensor hasil penelitian yang didapat rata-rata error sebesar $1 \%$. Semua penelitian yang dilakukan hanya fokus pada monitoring menggunakan komunikasi jaringan internet yang tentu saja menambah biaya, selain itu tidak ada pemberitahuan baik kepada dokter atau keluarga pasien beresiko jika terjadi sesuatu pada pasien.

Pada penelitian ini kami membuat alat portable dengan ukuran kecil berbiaya rendah untuk mengawasi dan memantau pasien beresiko vertigo dan sinkop apakah terjadi insiden pusing, jatuh atau tidak. Berbagai metode khusus telah dikembangkan untuk mendeteksi jatuh $[17,18,19]$. Pendekatan deteksi jatuh yang ada dikategorikan menjadi tiga kelas yaitu: (i) wearable sensor based, (ii) ambience sensor based and (iii) vision based [20]. Wearable sensor based, digunakan untuk efisiensi biaya perangkat, pemasangan dan penataan desain juga tidak rumit. Oleh karena itu, perangkatnya relatif mudah beroperasi.[21] Selain itu alat ini juga dilengkapi dengan tombol panic button serta RTC (Real Time Clock) untuk pengingat minum obat bagi pasien jika sedang mengkonsumsi obat rutin dengan output suara dan modul GPS untuk tracking position. Tujuan penelitian adalah merancang dan membuat alat menggunakan sensor accelerometer yang berguna untuk mengetahui kondisi penderita vertigo dan sinkop. Diharapkan dengan alat ini dapat meringankan hasil pengujian. Tahapan penelitian Alat Pengawasan Untuk Penderita Vertigo dan Sinkop Berbasis Mikrokontroler dapat dilihat pada Gambar 1.

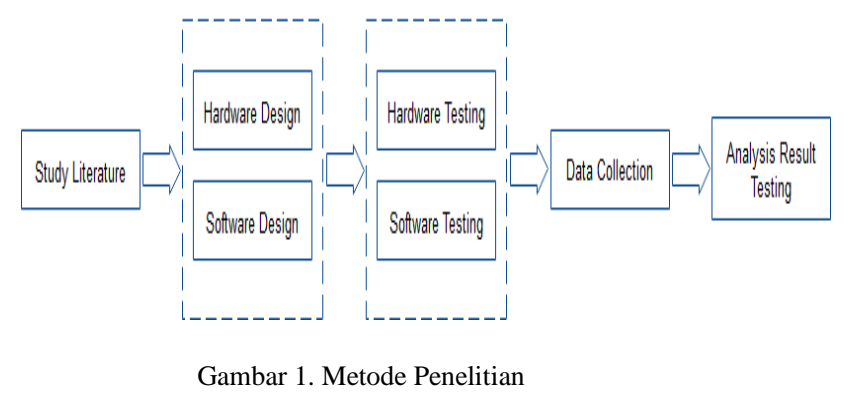

\subsection{Perancangan Sistem}

Alat ini menggunakan sensor accelerometer untuk mengetahui sudut kemiringan dari sensor yang diletakkan pada prototype box agar dapat diketahui kondisi dari pasien vertigo. Sensor accelerometer ditentukan menjadi 3 kondisi yaitu, baik-baik saja, pusing (terjatuh secara tidak sengaja) dan jatuh. Pada saat kondisi baik-baik saja akan berjalan dengan normal dan untuk kondisi normal ini juga disediakan push button untuk tombol panik yang bisa digunakan penderita vertigo jika membutuhkan pertolongan. Selanjutnya pada kondisi kedua yaitu pusing, pasien mengalami pusing dan terjatuh secara tidak sengaja menggerakkan badan karena keseimbangan badan yang terganggu sehingga sensor accelerometer akan membaca pergerakan dari badan pasien yang sedang mengalami pusing. Pada saat kondisi pusing DF-Player akan menanyakan terlebih dahulu keadaan penderita apakah baik-baik saja, apabila kondisi pasien tidak baik maka pasien bisa menekan push button untuk meminta bantuan dengan mengirim notifikasi SMS dan mengaktifkan DF-Player. Pada kondisi terakhir yaitu jatuh, sensor kemiringan akan mendeteksi kemiringan pasien yang jatuh apakah terjatuh kekiri, kekanan, kebelakang dan kedepan. Perancangan system Alat Pengawasan Untuk Penderita Vertigo dan Sinkop Berbasis Mikrokontroler dapat dilihat pada Gambar 2. Selanjutnya mikrokontroler akan memproses kondisi bahwa pasien telah terjatuh. Kemudian DF-Player akan menanyakan keadaan pasien terlebih dahulu apakah pasien baik-baik saja, apabila tidak ada respon dari pasien maka Modul GSM SIM800L akan mengirimkan notifikasi SMS ke nomor telepon "0823 xxxx xxxx" sebagai notifikasi bahwa pasien terjatuh dan DF-Player akan berbunyi bahaya, apabila ada respon dari pasien

Jurnal RESTI (Rekayasa Sistem dan Teknologi Informasi) Vol . 4 No. 6 (2020) 1102 - 1109 
dengan menekan tombol reset maka pasien dinyatakan baik dan notifikasi SMS akan dibatalkan serta notifikasi bahaya tidak akan aktif. Alat ini juga menggunakan RTC sebagai pengingat bagi pasien untuk minum obat dan LCD Oled sebagai penampilan waktu dari RTC dan juga tanda bagi kondisi pasien. Misalkan pasien diharuskan minum obat setiap 6 jam sekali. Maka setelah RTC disetting maka setiap 6 jam DF-Player aktif sebagai alarm atau tanda untuk mengingatkan pasien untuk meminum obat.

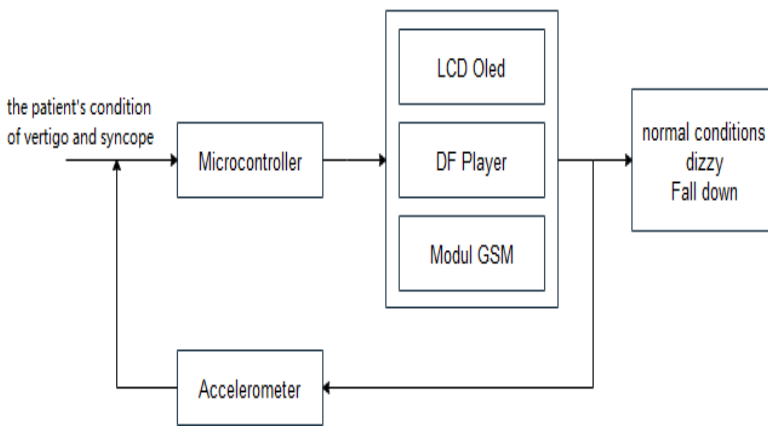

Gambar 2. Blok Diagram Sistem

\subsection{Perancangan Perangkat Keras (Hardware)}

Rangkaian ini terdiri dari pendeteksi sudut kemiringan menggunakan accelerometer MPU6050, push button, RTC, DF Player, Modul GSM SIM800L, Baterai terhubung ke pin 5V dan GND, arduino nano berfungsi sebagai mikrokontroler seperti yang terlihat pada gambar 3. Sensor accelerometer MPU6050 terhubung pada pin A4, A5 pada mikrokontroler mendeteksi kemiringan posisi pasien yang diletakkan pada protoype tas saat mengalami perubahan posisi yang dibagi menjadi beberapa kondisi. Untuk menentukan kondisi pasien pada sensor accelerometer dapat dilihat pada Tabel 1.

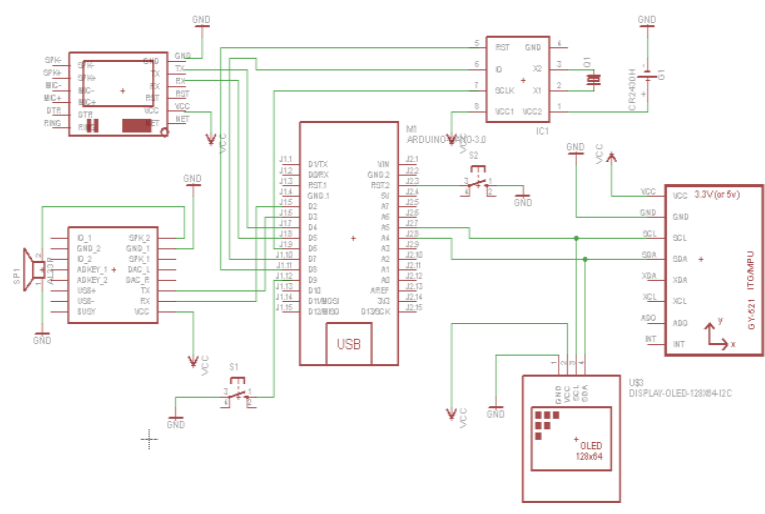

Gambar 3. Rangkaian elektronika alat deteksi jatuh
Tabel 1. Nilai Sensor Accelerometer Untuk deteksi jatuh

\begin{tabular}{|c|c|c|c|c|}
\hline \multicolumn{3}{|c|}{ Nilai Test } & \multirow{2}{*}{$\begin{array}{c}\text { Kondisi } \\
\text { Pasien Kiri } \\
\text { dan Kanan }\end{array}$} & \multirow{2}{*}{$\begin{array}{c}\text { Kondisi } \\
\text { Pasien depan } \\
\text { dan belakang }\end{array}$} \\
\hline $\mathbf{X}$ & $\mathbf{Y}$ & $\mathbf{Z}$ & & \\
\hline$<-35$ & $\begin{array}{c}-125 \text { to } \\
125\end{array}$ & $\begin{array}{c}-125 \text { to } \\
125\end{array}$ & $\begin{array}{c}\text { Baik } \\
\left(0^{\circ}-50^{\circ}\right)= \\
Y \\
\left(40^{\circ}-90^{\circ}\right)= \\
X\end{array}$ & $\begin{array}{c}\text { Baik } \\
\left(0^{\circ}-50^{\circ}\right)=Z \\
\left(40^{\circ}-90^{\circ}\right)= \\
X\end{array}$ \\
\hline $\begin{array}{c}(-35) \text { to } \\
(-10)\end{array}$ & $\begin{array}{c}-150 \text { to } \\
-125 \\
125 \text { to } \\
150\end{array}$ & $\begin{array}{c}-150 \text { to }- \\
125 \\
125 \text { to } \\
150\end{array}$ & $\begin{array}{c}\text { Pusing } \\
\left(50^{\circ}-70^{\circ}\right)= \\
Y \\
\left(40^{\circ}-20^{\circ}\right)= \\
X\end{array}$ & $\begin{array}{c}\text { Pusing } \\
\left(50^{\circ}-70^{\circ}\right)= \\
Z \\
\left(40^{\circ}-20^{\circ}\right)= \\
X\end{array}$ \\
\hline$>-10$ & $\begin{array}{l}-150< \\
Y>150\end{array}$ & $\begin{array}{l}-150< \\
Y>150\end{array}$ & $\begin{array}{c}\text { Jatuh } \\
\left(70^{\circ}-90^{\circ}\right)= \\
Y \\
\left(20^{\circ}-0^{\circ}\right)= \\
X\end{array}$ & $\begin{array}{c}\text { Jatuh } \\
\left(70^{\circ}-90^{\circ}\right)= \\
Z \\
\left(20^{\circ}-0^{\circ}\right)= \\
X\end{array}$ \\
\hline
\end{tabular}

Sensor accelerometer menggunakan koneksi I2C (SDA dan SCL) dimana SDA terhubung ke pin A4 dan SCL ke pin A5 mikrokontroler. Baterai sebagai sumber tegangan mobile untuk sistem ini terhubung ke $+5 \mathrm{~V}$ dan GND mikrokontroler dan $+4 \mathrm{~V}$ ke modul GSM SIM800L. Untuk mendapatkan tegangan sebesar +4VDC diperlukan sebuah DC-DC converter. Tombol panic terhubung pada pin 9, tombol reset terhubung pada pin RST dan GND pada mikrokontroler. Pin 2, dan 3 digunakan sebagai jalur masuknya data keluaran untuk mengirimkan SMS pada SIM800L. Pin RX, dan TX digunakan sebagai jalur masuknya data keluaran untuk mengaktifkan DF-Player. Alat yang dibuat akan ditempatkan di ikat pinggang pasien. Rancangan box alat dapat diluhat pada Gambar 4.

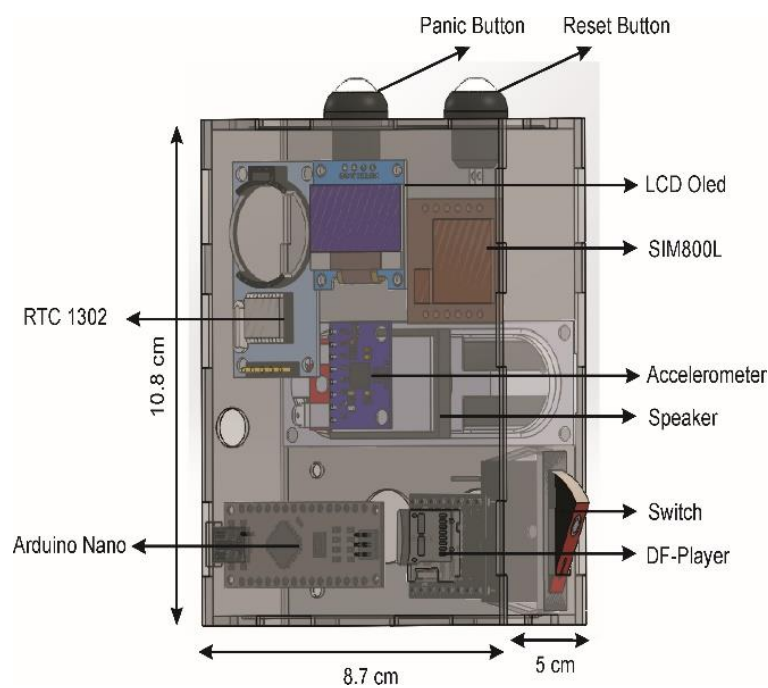

Gambar 4. Perancangan Prototype Alat 


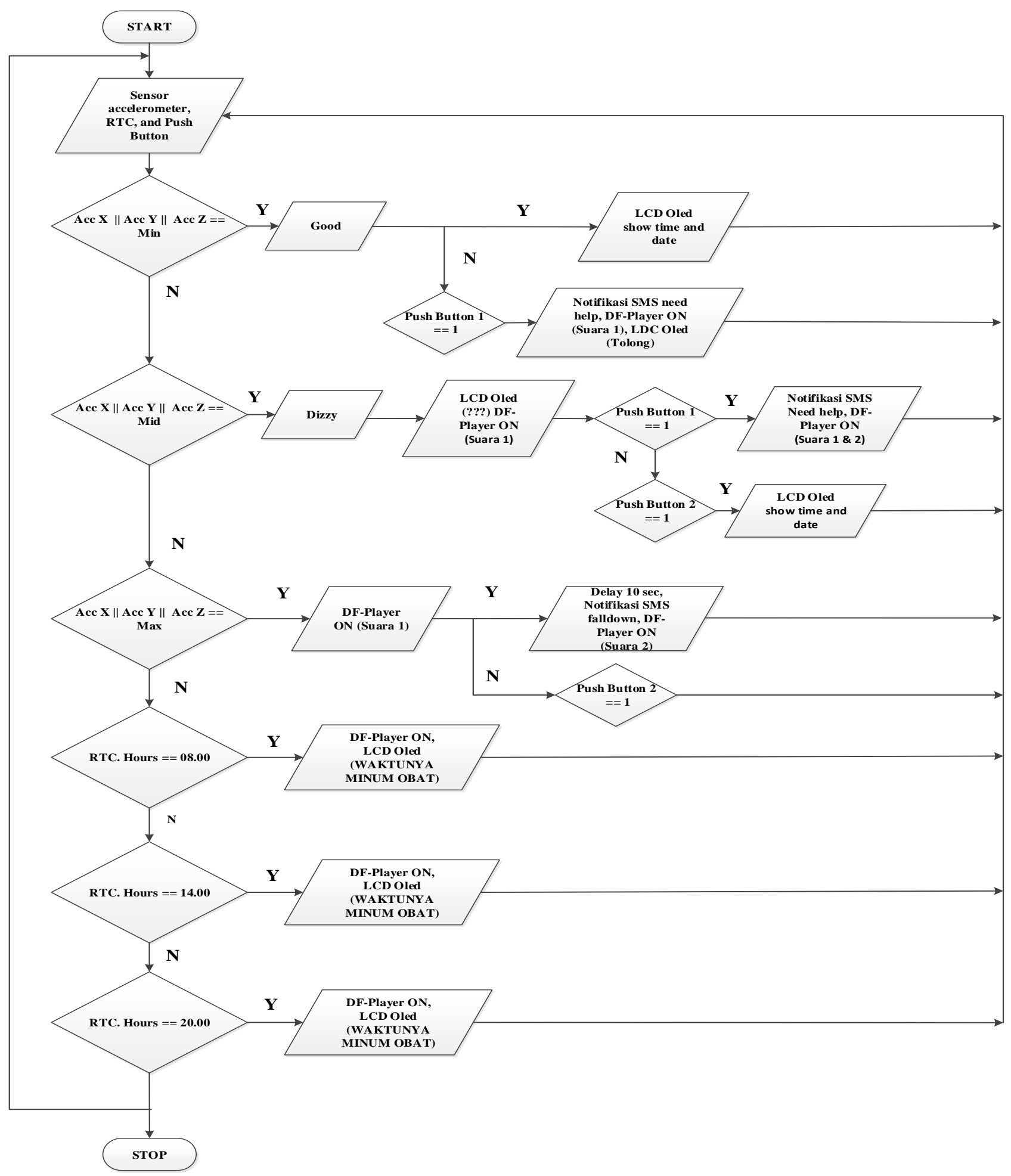

Gambar 5. Flowchart Alat deteksi Jatuh

\subsection{Perancangan Perangkat Lunak (Software)}

Flowchart alat monitoring pasien vertigo dengan notifikasi sms dapat dilihat pada gambar 5. Proses dimulai dari inisialiasi I/O. Pada kondisi Good LCD akan menampilkan jam dan tanggal, apabila push button panik ditekan DF Player akan berbunyi minta tolong, LCD akan menampilkan tulisan "TOLONG" dan SIM800L akan mengirim SMS. Pada kondisi Pusing LCD akan menampilkan "???” serta DF Player akan menanyakan keadaan pasien, apabila push button panik ditekan DF Player akan meminta bantuan serta SIM800L akan mengirim SMS, dan apabila push button reset ditekan maka DF Player tidak berbunyi 
serta SIM800L tidak mengirim SMS, LCD akan menampilkan jam dan tanggal. Pada kondisi Jatuh LCD akan menampilkan "???" serta DF Player akan menanyakan keadaan pasien, selama 10 detik tidak ada respon maka SMS akan ter kirim LCD akan menampilkan "JATUH" dan DF Player akan berbunyi. Jika pasien menekan push button reset pada saat terjatuh maka SMS akan dibatalkan dan pasien dinyatakan baik-baik saja. Pada saat baik-baik saja DF Player akan mengingatkan minum obat 3 kali sehari dan tampilan LCD "WAKTUNYA MINUM OBAT

\section{Hasil dan Pembahasan}

Langkah selanjutnya adalah pengujian alat pengawasan untuk penderita vertigo dan sinkop berbasis mikrokontroler, pengujian ini bertujuan untuk mengetahui kelebihan dan kekurangan dari sistem yang telah dibuat Pengujian dilaksanakan tiga tahap. Pertama pengujian performance sistem, kedua pengujian notifikasi alat dan ketiga pengujian alat keseluruhan. Alat yang berbentuk prototype tas ini kemudian dipasang pada pasien, seperti yang terlihat pada Gambar 6.

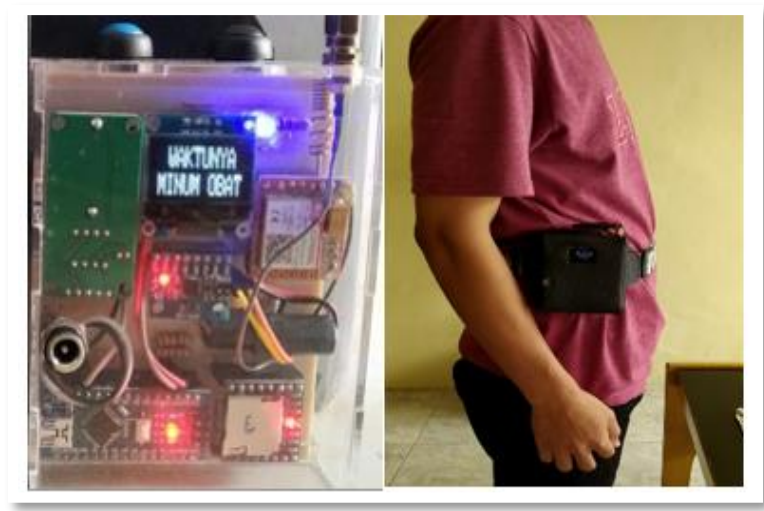

Gambar 6. Pemasangan alat pendeteksi jatuh pada tubuh

\subsection{Pengujian Performance Sistem}

Pengujian ini dilakukan untuk mengetahui performance alat, baik pasien pada kondisi pusing,aktifitas biasa dan deteksi jatuh. Dimulai dengan menguji sensor kemiringan pada accelerometer, kami mengambil data keluaran pada sumbu $\mathrm{X}, \mathrm{Y}$, dan sumbu $\mathrm{Z}$ untuk mendeteksi keadaan pasien. Data yang diambil berdasarkan kemiringan sudut $0^{\circ}, 50^{\circ}, 70^{\circ}$, dan $90^{\circ} \mathrm{ke}$ belakang dan ke kiri kemudian data sensor ditampilkan pada serial monitor, sehingga didapatkan hasilnya sesuai dengan Table 1.

Berdasarkan Tabel 1 pada saat kondisi pasien baik-baik saja sensor accelerometer dikemiringan $0^{\circ}-50^{\circ}$ pada sumbu Y dan $90^{\circ}-40^{\circ}$ pada smbu $\mathrm{X}$, nilai sensor menunjukan -125 s/d 125 pada sumbu Y, nilai sensor < -35 pada sumbu X. Untuk kondisi pusing nilai sensor yang diambil adalah pada kemiringan $50^{\circ}-70^{\circ}$ pada sumbu Y dan $40^{\circ}-20^{\circ}$ pada sumbu $\mathrm{X}$, nilai sensor menunjukan $-150 \mathrm{~s} / \mathrm{d}-125$ dan $125 \mathrm{~s} / \mathrm{d} 150$ pada sumbu $\mathrm{Y}$, nilai sensor $-35 \mathrm{~s} / \mathrm{d}-10$ pada sumbu $\mathrm{X}$. Untuk kondisi jatuh nilai sensor yang diambil adalah pada kemiringan $70^{\circ}-0^{\circ}$ pada sumbu $\mathrm{Y}$ dan $20^{\circ}-0^{\circ}$ pada sumbu X, nilai sensor menunjukan $-150<\mathrm{Y}>150$ pada sumbu $Y$, nilai sensor $>-10$ pada sumbu $X$, untuk arah kekiri dan kekanan dengan titik putar pada sumbu $\mathrm{Z}$, dan apabila arah depan dan belakang sumbu Y akan diganti dengan sumbu $\mathrm{Z}$ dan titik putar berada pada sumbu Y.

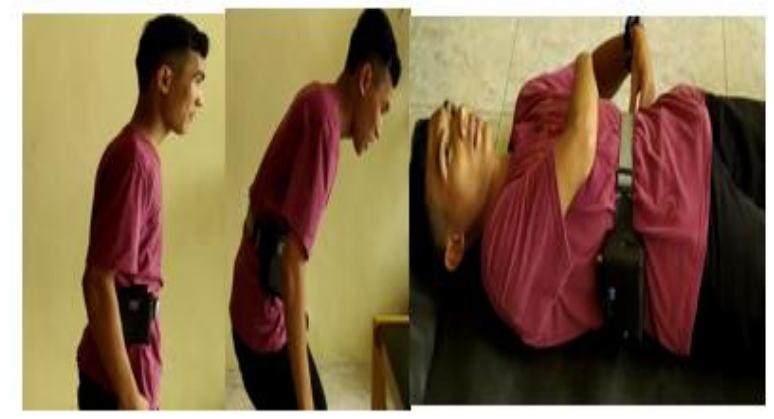

Gambar 7. Pengujian alat monitoring pasien vertigo dan sinkop

Perubahan nilai sudut akan mempengaruhi nilai sensor accelero. Semakin besar perubahan sudut semakin besar pula nilai sensor accelero. Jadi ketika nilai sensor accelero menunjukkan nilai $>150$ atau lebih maka bisa dikatakan penderita vertigo terjatuh. Kemudian DFPlyer akan berbunyi dan dalam waktu 10 detik tidak ada respon dari pasien maka SIM800L akan mengirim SMS. Selanjutnya dilakukan pengujian gerakan dalam tiga posisi untuk mendeteksi pusing yang tiba-tiba dialami pasien. Hasil pengujian dapat dilihat pada table 2.

Tabel 2. Tes deteksi pusing pada aktivitas rutin

\begin{tabular}{|c|c|c|c|c|c|c|}
\hline \multirow[t]{2}{*}{ Posisi } & \multirow[t]{2}{*}{$\begin{array}{c}\text { Jumlah } \\
\text { Percobaan }\end{array}$} & \multicolumn{2}{|c|}{$\begin{array}{l}\text { Pemberitahuan } \\
\text { Pusing melalui } \\
\text { panggilan } \\
\text { telepon }\end{array}$} & \multirow[t]{2}{*}{$\begin{array}{c}\text { Akurasi } \\
\%\end{array}$} & \multicolumn{2}{|c|}{$\begin{array}{c}\text { Deteksi } \\
\%\end{array}$} \\
\hline & & Yes & No & & Yes & No \\
\hline $\begin{array}{l}\text { Duduk- } \\
\text { Berdiri }\end{array}$ & 10 & 8 & 2 & 80 & & \\
\hline $\begin{array}{l}\text { Berdiri- } \\
\text { Berjalan }\end{array}$ & 10 & 8 & 2 & 80 & 83.3 & 16.67 \\
\hline $\begin{array}{l}\text { Berjalan- } \\
\text { Duduk }\end{array}$ & 10 & 9 & 1 & 90 & & \\
\hline Total & 30 & 25 & 5 & & & \\
\hline
\end{tabular}

Dari tiga puluh kali hasil percobaan untuk pengujian pada table 2, 83\% alat dapat mendeteksi pusing pasien pada aktifitas biasa, dengan tingkat akurasi sekitar $80 \%$ sampai dengan $90 \%$. Selanjutnya dilakukan pengujian deteksi alat untuk kejadian jatuh dan tengkurap. Hasil pengujian dapat dilihat pada tabel 3 .

Table 3. Tes deteksi jatuh pada system

\begin{tabular}{cccccccc}
\hline Kategori & $\begin{array}{c}\text { Jumlah } \\
\text { Percobaan }\end{array}$ & \multicolumn{2}{c}{$\begin{array}{c}\text { Notification } \\
\text { Jatuh }\end{array}$} & $\begin{array}{c}\text { Accuracy } \\
\%\end{array}$ & $\begin{array}{c}\text { Detection } \\
\%\end{array}$ \\
\cline { 2 - 4 } & & Yes & No & & & \\
\hline Tengkurap & 10 & 9 & 1 & & 90 & Yes & No \\
Telentang & 10 & 9 & 1 & 90 & 90 & 10
\end{tabular}


Total

20

$18 \quad 2$

Berdasarkan percobaan pada tabel 3, beberapa aktifitas jatuh seperti jatuh terlentang dan jatuh tengkurap $90 \%$ dapat dideteksi oleh sistem sebagai aktifitas jatuh dengan tingkat akurasi $90 \%$.

\subsection{Pengujian Notifikasi Alat}

Pengujian ini dilakukan untuk mengetahui apakah alat dapat mengirim notifikasi sms dan mengetahui posisi jika pasien pusing dan jatuh. Untuk menentukan seberapa akurat pembacaan koordinat lokasi yang ditangkap oleh satelit GPS menggunakan modul Ublox Neo-7M dengan menghitung selisih pergeseran titik pembacaan koordinat (latitude dan longitude) dengan nilai koordinat yang didapatkan dari aplikasi Google Maps. Koordinat posisi pengujian ditetapkan yaitu $0.927869,100.433592$ yang terlihat pada gambar 8 .

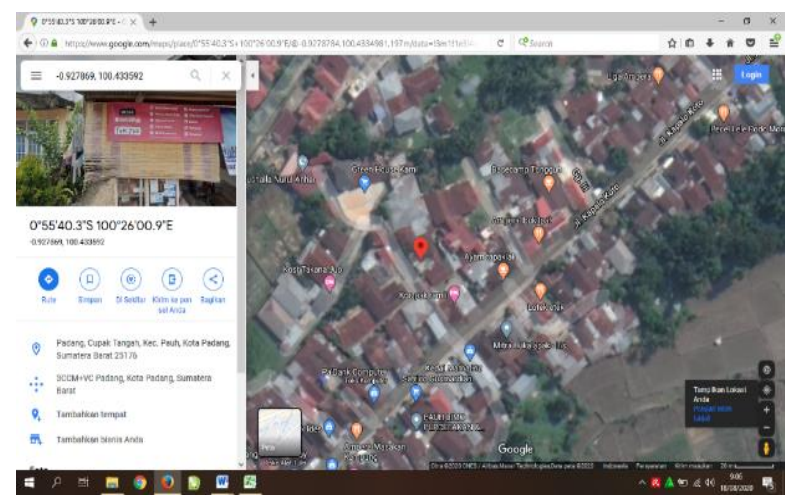

Gambar 8. Posisi pengujian GPS

Titik koordinat ini diambil dengan memanfaatkan aplikasi Google Maps berdasarkan lokasi dan posisi sesungguhnya.. Penghitungan jarak anatara dua titik pada permukaan lengkung (teori Bumi bulat) dengan memanfaatkan nilai latitude dan longitude dapat menggunakan metode Haversine Formula [22]. Metode ini adalah persamaan untuk penggunaan navigasi agar dapat menghitung jarak antar koordinat pada system proyeksi geografis Derajat Desimanl $\left(\mathrm{DD}^{\circ}\right)$.

$$
2 r \sin ^{-1}\left(\sqrt{\sin ^{2}\left(\frac{\Delta \varphi}{2}\right)+\cos (\varphi 1) \cos (\varphi 2) \sin ^{2}\left(\frac{\Delta \lambda}{2}\right)}\right)
$$

Dimana $\mathrm{d}$ : jarak, $\mathrm{r}:$ radius bumi (rerata radius $=6.371$ $\mathrm{km}, \varphi$ : latitude $\Delta \varphi: \varphi 2-\varphi 1 \lambda$ : longitude $\Delta \lambda: \lambda 2-\lambda 1$. Hasil Pergeseran titik pembacaan GPS antara google map dan modul gps menggunakan Haversine Formula dapat dilihat pada tabel 4.

Tabel 4. Selisih Pergeseran titik pembacaan GPS ke titik pengujian

\begin{tabular}{|c|c|c|c|c|c|}
\hline \multirow[t]{2}{*}{ No } & \multicolumn{2}{|l|}{ Google Map } & \multicolumn{2}{|c|}{ Modul GPS } & \multirow{2}{*}{$\begin{array}{l}\text { Selisih } \\
\text { (meter } \\
\text { ) }\end{array}$} \\
\hline & Latitude1 & Longitude1 & Latitude2 & Longitude2 & \\
\hline \multirow[t]{2}{*}{1} & & & & & 4,1003 \\
\hline & $-0,927869$ & 100,433592 & $-0,927845$ & 100,433620 & 52863 \\
\hline \multirow[t]{2}{*}{2} & & & & & 3,1605 \\
\hline & $-0,927869$ & 100,433592 & $-0,927847$ & 100,433610 & 84834 \\
\hline 3 & $-0,927869$ & 100,433592 & $-0,927848$ & 100,433610 & $\begin{array}{l}3,0753 \\
26322\end{array}$ \\
\hline
\end{tabular}

\begin{tabular}{|c|c|c|c|c|c|}
\hline 4 & & & & & 2,9917 \\
\hline & $-0,927869$ & 100,433592 & $-0,927849$ & 100,433610 & 71392 \\
\hline 5 & $-0,927869$ & 100,433592 & $-0,927850$ & 100,433610 & $\begin{array}{l}2,9100 \\
66789 \\
\end{array}$ \\
\hline 6 & & & -0.927850 & & 2,9100 \\
\hline & $-0,927869$ & 100,433592 & $-0,92 / 050$ & 100,433610 & 66789 \\
\hline 7 & $-0,927869$ & 100,433592 & $-0,927850$ & 100,433610 & $\begin{array}{l}2,9100 \\
66789\end{array}$ \\
\hline 8 & & & & & 3,0753 \\
\hline & $-0,927869$ & 100,433592 & $-0,927848$ & 100,433610 & 26322 \\
\hline 9 & & & & & 3,0753 \\
\hline & $-0,927869$ & 100,433592 & $-0,927848$ & 100,433610 & 26322 \\
\hline 10 & & & & & 0,2486 \\
\hline & $-0,927869$ & 100,433592 & $-0,927870$ & 100,433590 & 13123 \\
\hline 11 & & & & & 0,9169 \\
\hline & $-0,927869$ & 100,433592 & $-0,927861$ & 100,433590 & 29009 \\
\hline 12 & & & & & 0,5987 \\
\hline & $-0,927869$ & 100,433592 & $-0,927864$ & 100,433590 & 91671 \\
\hline 13 & & & & & 0,3144 \\
\hline & $-0,927869$ & 100,433592 & $-0,927867$ & 100,433590 & 85862 \\
\hline 14 & & & & & 0,2486 \\
\hline & $-0,927869$ & 100,433592 & $-0,927868$ & 100,433590 & 13123 \\
\hline 15 & & & & & 0,2223 \\
\hline & $-0,927869$ & 100,433592 & $-0,927869$ & 100,433590 & 60505 \\
\hline & & Rata- & & & 2,394 \\
\hline
\end{tabular}

Pada Tabel 4 terdapat nilai latitude1 dan longitude1 yang mana nilainya diambil dari titik pengujian yang memanfaatkan aplikasi Google Maps pada smartphone. Nilai latitude2 dan longitude 2 didapatkan dari hasil data dari pengujian modul GPS U-blox Neo-7M. Sehingga akan didapatkan nilai selisih pergeseran titik yang pembacaan oleh modul GPS dari titik koordinat yang diukur menggunakan metode Haversine Formula. Dipengujian ke-10 hingga pengujian ke-15 jarak pembacaan oleh modul GPS sudah hampir mendekati lokasi titik pengujian. Hal ini dikarenakan sistem navigasi GPS saat pertama kali dihidupkan akan berusaha mendengar ke semua satelit dan menunggu laporan lokasi terdekat (TTFF / Time To First Fix). Untuk mendengarkan semua satelit dan memilih lokasi terdekat akan membutuhkan waktu lama karena satelitsatelit navigasi akan selalu bergerak dan posisinya tidak sama. Selanjutnya dilakukan pengamatan dan pengujian modul terhadap posisi pasien seperti yang terlihat pada Tabel 5 .

Tabel 5. Hasil pengamatan pengujian modul GPS

\begin{tabular}{|c|c|c|}
\hline Data masukan & $\begin{array}{l}\text { Yang } \\
\text { diharapkan }\end{array}$ & Pengamatan \& pengujian \\
\hline $\begin{array}{l}\text { Data dari modul } \\
\text { (latitude \& \& } \\
\text { longitude) }\end{array}$ & $\begin{array}{l}\text { Modul GPS } \\
\text { dapat } \\
\text { menentukan } \\
\text { lokasi } \\
\text { kecelakaan } \\
\text { dengan tepat }\end{array}$ & $\begin{array}{l}\text { Modul GPS dapat } \\
\text { mendeteksi koordinat } \\
\text { latitude dan longitude } \\
\text { pengujian dengan baik, } \\
\text { dengan rata-rata selisih } \\
\text { pergeseran titik } \\
\text { pembacaan modul } \\
\text { sekitar 2,39 meter. }\end{array}$ \\
\hline
\end{tabular}

Pengujian modul GPS dilakukan untuk mengetahui seberapa akurat modul GPS Neo-7M dalam menentukan titik koordinat lokasi karena nilai akurasi pembacaan modul GPS sangat berpengaruh pada proses tracking lokasi kecelakaan untuk menemukan lokasi korban. Modul GPS pada penelitian ini dapat 
membaca koordinat lokasi dengan baik apabila dibiarkan dalam kondisi ON beberapa menit setelah modul mendapatkan sinyal GPS.

\subsection{Pengujian Alat Keseluruhan}

Untuk dapat mengetahui keberhasilan kerja dari alat/sistem maka dilakukan pengujian secara langsung dengan menempatkan alat pada pinggang pasien, sensor kemiringan hingga panggilan telepon dan pengiriman SMS. Hasil dari pengujian keseluruhan sistem dapat dilihat pada tabel 6. Setelah modul MPU6050 mendeteksi kondisi pasien pada nilai akselerasi $\left(50^{\circ}-70^{\circ}\right)=\mathrm{Y}\left(40^{\circ}-20^{\circ}\right)=\mathrm{X}$, maka SMS dan panggilan telepon oleh sistem akan dijalankan. Setelah SMS dikirimkan oleh sistem ke nomor penerima seperti pada gambar 7, maka tracking lokasi kecelakaan dapat dilakukan dengan mengklik tautan yang ada pada pesan. Penekanan link/tautan pada gambar 9 akan menampilkan tampilan aplikasi Google Maps seperti Gambar 10.

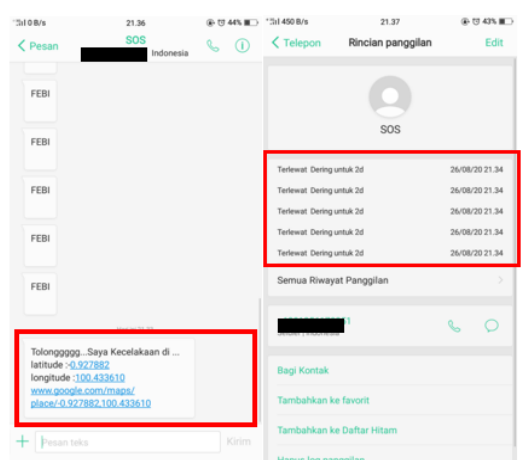

Gambar 9. SMS peringatan \& panggilan telepon pada nomor yang berada di lokasi pengujian

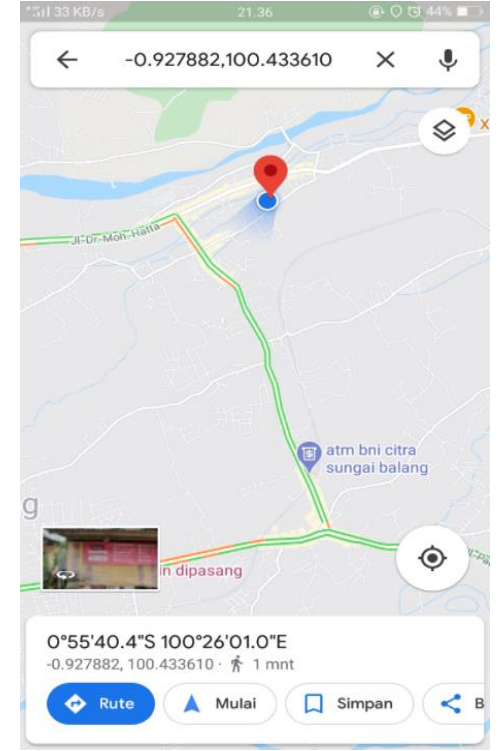

Gambar 10. Pelacakan posisi dari pengiriman link sms yang berada di lokasi pengujian

Gambar 10 menunjukkan bahwa GPS telah mendeteksi lokasi pengujian di koordinat -0,927882,100.433610, artinya jika dibandingkan dengan lokasi pembacaan google maps maka berdasarkan Metoda Haversine Formula rata-rata jarak pergeseran titik pembacaan GPS adalah 2,5 meter. Sistem dengan notifikasi SMS dan tracking pada google maps dapat bekerja dengan baik, mulai dari pendeteksi kemiringan, alarm, pengiriman SMS dan panggilan telepon dengan data dari modul GPS, serta melakukan pembatalan pengiriman SMS dan panggilan telepon

Tabel 6. Hasil pengujian Alat keseluruhan

\begin{tabular}{|c|c|c|c|c|c|c|c|}
\hline Kondisi & $\begin{array}{l}\text { Kondisi Pasien } \\
\text { Kiri dan Kanan }\end{array}$ & $\begin{array}{l}\text { Kondisi } \\
\text { Pasien } \\
\text { depan dan } \\
\text { belakang }\end{array}$ & GPS & $\begin{array}{c}\text { Push } \\
\text { Button 1 } \\
\text { (Panik) }\end{array}$ & $\begin{array}{c}\text { Push } \\
\text { Button 2 } \\
\text { (Reset) }\end{array}$ & Notifikasi & Keterangan \\
\hline Baik & $\begin{aligned}\left(0^{\circ}-50^{\circ}\right) & =\mathrm{Y} \\
\left(40^{\circ}-90^{\circ}\right) & =\mathrm{X}\end{aligned}$ & $\begin{array}{c}\left(0^{\circ}-50^{\circ}\right) \\
\quad=Z \\
\left(40^{\circ}-90^{\circ}\right) \\
\quad=X\end{array}$ & $\begin{array}{l}-0.927853 \\
100.433610\end{array}$ & Off & Off & Tidak mengirim sms & Sesuai \\
\hline Pusing & $\begin{array}{c}\text { Pusing } \\
\left(50^{\circ}-70^{\circ}\right)=\mathrm{Y} \\
\left(40^{\circ}-20^{\circ}\right)=\mathrm{X}\end{array}$ & $\begin{array}{c}\text { Pusing } \\
\left(50^{\circ}-70^{\circ}\right) \\
=Z \\
\left(40^{\circ}-20^{\circ}\right) \\
=X\end{array}$ & $\begin{array}{l}-0.927854 \\
100.433610\end{array}$ & $\begin{array}{l}\text { Off } \\
\text { On } \\
\text { Off }\end{array}$ & $\begin{array}{l}\text { Off } \\
\text { Off } \\
\text { On }\end{array}$ & $\begin{array}{c}\text { Tidak mengirim SMS } \\
\text { Mengirim SMS } \\
\text { Tidak mengirim SMS }\end{array}$ & $\begin{array}{l}\text { Sesuai } \\
\text { Sesuai }\end{array}$ \\
\hline Jatuh & $\begin{array}{c}\text { Jatuh } \\
\left(70^{\circ}-90^{\circ}\right)=\mathrm{Y} \\
\left(20^{\circ}-0^{\circ}\right)=\mathrm{X}\end{array}$ & $\begin{array}{c}\text { Jatuh } \\
\left(70^{\circ}-90^{\circ}\right) \\
=Z \\
\left(20^{\circ}-0^{\circ}\right) \\
=X\end{array}$ & $\begin{array}{l}-0.927855 \\
100.433610\end{array}$ & $\begin{array}{l}\text { Off } \\
\text { Off }\end{array}$ & On & $\begin{array}{c}\text { Mengirim SMS } \\
\text { Tidak Mengirim SMS }\end{array}$ & $\begin{array}{l}\text { Sesuai } \\
\text { Sesuai } \\
\text { Sesuai }\end{array}$ \\
\hline
\end{tabular}

Jurnal RESTI (Rekayasa Sistem dan Teknologi Informasi) Vol . 4 No. 6 (2020) 1102 - 1109 


\section{Kesimpulan}

Pada penelitian ini, kami membuat alat portable berbiaya rendah untuk mengawasi dan memantau pasien beresiko vertigo apakah terjadi insiden pusing, jatuh atau tidak. Hasil pengujian yang dilakukan pada alat alat dapat melakukan pengiriman SMS dan panggilan telepon pada sudut $\left(50^{\circ}-70^{\circ}\right)=\mathrm{Y}\left(40^{\circ}-20^{\circ}\right)=\mathrm{X}$, di kondisi pingsan dan jatuh. Hasil pengujian modul navigasi membuktikan bahwa modul GPS dapat menentukan lokasi dengan tepat dengan pergesaran posisi pembacaan modul GPS ke titik pengujian kecil dengan rata-rata 2,97 meter.

\section{Daftar Pustaka}

[1] D. Sura and S. Newell, "Vertigo-diagnosis and management in the primary care," Br J Med Pr., vol. 3, no. 4, p. a351, 2010, [Online]. Available: http://www.bjmp.org/content/vertigodiagnosis-and-management-primary-care.

[2] P. Gnerre, C. Casati, M. Frualdo, M. Cavalleri, and S. Guizzetti, "Management of vertigo: From evidence to clinical practice," Ital. J. Med., vol. 9, no. 2, pp. 180-192, 2015, doi: 10.4081/itjm.2015.437.

[3] T. L. Thompson and R. Amedee, "Vertigo: A review of common peripheral and central vestibular disorders," Ochsner J., vol. 9, no. 1 , pp. 20-26, 2009.

[4] S. K. Kidd, C. Doughty, and S. Z. Goldhaber, "Syncope (Fainting)," Circulation, vol. 133, no. 16, pp. e600-e602, 2016, doi: 10.1161/CIRCULATIONAHA.115.017308.

[5] P. Müller-Barna et al., "TeleVertigo: Diagnosing Stroke in Acute Dizziness: A Telemedicine-Supported Approach," Stroke, vol. 50, no. 11, pp. 3293-3298, 2019, doi: 10.1161/STROKEAHA.119.026505.

[6] A. Moya et al., "Guidelines for the diagnosis and management of syncope (version 2009)," Eur. Heart J., vol. 30, no. 21, pp. 2631-2671, 2009, doi: 10.1093/eurheartj/ehp298.

[7] M. Irmansyah, et al., "Low Cost Heart Rate Portable Device for Risk Patients with IoT and Warning System," IEEE International Conference on Applied Information Technology and Innovation (ICAITI), pp. 46-49, 2018.

[8] M. G. Ayoub, M. N. Farhan, and M. S. Jarjees, "Streaming inpatient BPM data to the cloud with a real-time monitoring system," Telkomnika (Telecommunication Comput. Electron. Control., vol. 17, no. 6, pp. 3120-3125, 2019, doi: 10.12928/TELKOMNIKA.v17i6.13263.

[9] M. Subito, M. Ikhlayel, and E. Setijadi, "Internet of thingsbased vital sign monitoring system," Int. J. Electr. Comput. Eng., vol. 10, no. 6, pp. 5891-5898, 2020, doi: 10.11591/ijece.v10i6.pp5891-5898.

[10] K. Kalaithasan, N. A. M. Radzi, and H. Z. Abidin, "Internet of things application in monitoring sick building syndrome," Indones. J. Electr. Eng. Comput. Sci., vol. 12, no. 2, pp. 505512, 2018, doi: 10.11591/ijeecs.v12.i2.pp505-512.

[11] M. Irmansyah, E. Madona, and A. Nasution, "Design and application of portable heart rate and weight measuring tool for premature baby with microcontroller base," Int. J. GEOMATE, vol. 17, no. 61, pp. 195-201, 2019, doi: 10.21660/2019.61.ICEE12.

[12] S. Trivedi and A. N. Cheeran, "Android based health parameter monitoring," Proc. 2017 Int. Conf. Intell. Comput. Control Syst. ICICCS 2017, vol. 2018-Janua, pp. 1145-1149, 2018, doi: 10.1109/ICCONS.2017.8250646.

[13] Yuhefizar, A. Nasution, R. Putra, E. Asri, and D. Satria, "IoT: Heart Rate Monitoring Tool Using Android with Alert Messanger Telegram System," IOP Conf. Ser. Mater. Sci. Eng., vol. 846, no. 1, 2020, doi: 10.1088/1757899X/846/1/012014.

[14] M. Islam et al., "Android based heart rate monitoring and automatic notification system," 5th IEEE Reg. 10 Humanit. Technol. Conf. 2017, R10-HTC 2017, vol. 2018-Janua, pp. 436-439, 2018, doi: 10.1109/R10-HTC.2017.8288993.

[15] R. T. Hameed, O. A. Mohamad, O. T. Hamid, and N. Ţăpuş, "Patient monitoring system based on e-health sensors \& web services," Proc. 8th Int. Conf. Electron. Comput. Artif. Intell. ECAI 2016, 2017, doi: 10.1109/ECAI.2016.7861089.

[16] V. Jones, V. Gay, and P. Leijdekkers, "Body sensor networks for mobile health monitoring: Experience in Europe and Australia," 4th Int. Conf. Digit. Soc. ICDS 2010, Incl. CYBERLAWS 2010 1st Int. Conf. Tech. Leg. Asp. e-Society, pp. 204-209, 2010, doi: 10.1109/ICDS.2010.41.

[17] A. Jefiza, E. Pramunanto, H. Boedinoegroho, and M. H. Purnomo, "Fall detection based on accelerometer and gyroscope using back propagation," Int. Conf. Electr. Eng. Comput. Sci. Informatics, vol. 2017-December, no. September, pp. 19-21, 2017, doi: 10.1109/EECSI.2017.8239149.

[18] Y. Lee, H. Yeh, K. H. Kim, and O. Choi, "A real-time fall detection system based on the acceleration sensor of smartphone," Int. J. Eng. Bus. Manag., vol. 10, pp. 1-8, 2018, doi: $10.1177 / 1847979017750669$.

[19] D. Aphairaj, M. Kitsonti, and T. Thanapornsawan, "Fall detection system with 3-axis accelerometer," J. Phys. Conf. Ser., vol. 1380, no. 1, 2019, doi: 10.1088/17426596/1380/1/012060.

[20] M. Mubashir, L. Shao, and L. Seed, "A survey on fall detection: Principles and approaches," Neurocomputing, vol. 100, pp. 144-152, 2013, doi: 10.1016/j.neucom.2011.09.037.

[21] A. Hakim, M. S. Huq, S. Shanta, and B. S. K. K. Ibrahim, "Smartphone Based Data Mining for Fall Detection: Analysis and Design," Procedia Comput. Sci., vol. 105, no. December 2016, pp. 46-51, 2017, doi: 10.1016/j.procs.2017.01.188.

[22] F. Farid and Y. Yunus, "Analisa Algoritma Haversine Formula Untuk Pencarian Lokasi Terdekat Rumah Sakit Dan Puskesmas Provinsi Gorontalo,” Ilk. J. Ilm., vol. 9, no. 3, pp. 353-355, 2017, doi: 10.33096/ilkom.v9i3.178.353-355. 